\title{
Effects of Pentobarbital and Dinitrophenol on Oxygen Consumption in Hypothyroid and Hyperthyroid Rats
}

\author{
Masashi KURAHASHI \\ Department of Physiology, Tokyo College of Pharmacy, Tokyo, Japan
}

Thyroid hormones stimulate the basal metabolic rate, and pentobarbital blocks the calorigenesis of thyroid hormones. These findings suggest that there is an interrelation between thyroid hormones and the sympathetic nerve systems. On the other hand thyroid hormones potentiate 2, 4-dinitrophenol (DNP)-induced calorigenesis, then this investigation was undertaken to ascertain that thyroid hormones potentiate DNP-induced caloigenesis, and to clarify the effects of pentobarbital on DNP-induced calorigenesis in hypothyroid and hyperthyroid rats.

\section{Materials and Method}

Adult male rats (Wister strain) weighing between $250 \mathrm{~g}$ and $300 \mathrm{~g}$ were used in this investigation. Hypothyroidism was produced by surgical thyroidectomy. Rats subjected to thyroidectomy were used for experiemnts more than 20 days after the operation. Hyperthyroidism was produced by an intraperitoneal injection of thyroxine, $100 \mu \mathrm{g} / 100 \mathrm{~g}$ body wt, for 5 days. Pentobarbital, $5 \mathrm{mg} / 100 \mathrm{~g}$ body wt, was injected intraperitoneally DNP $0.5-2.0 \mathrm{mg} / 100 \mathrm{~g}$ body $\mathrm{wt}$, was injected intraperitoneally. Oxygen consumption was measured by a closed-circuit method for an hour, just before the rats were injected and between 8 and $28 \mathrm{~min}$. after injection pentobarbital, between 0 and 180 after injection DNP.

\section{Results and Discussions}

Thyroxine potentiated DNP-induced calorigenesis, on the other hand thyroidectomy diminished DNP-induced calorigenesis. Pentobarbital blocked the calorigenesis and the potentiation of DNP-induced calorigenesis of thyroxine. In thyroidectomized rats, pentobarbital had little effect on DNP-induced calorigenesis.

From the results shown above, it is assumed that a part of calorigenesis and potemtiation of DNP-induced calorigenesis of thyroid hormones, depend on the sympathetic nerve system.

(See pp. 800 803) 


\section{甲摘及びチロキシン投与ラットの酸素消費量に対する \\ ペントバルビタール及びジニトロフェノールの効果}

東京薬科大学生理学教室

倉橋昌司

(昭和45年 3 月16日受付)

甲摘及びチロキシン投与ラットの酸素消費量に対するジニトロフェノール及びペントバルビタールと ジニトロフェノールの効果を検討した. 甲状腺状態が高いはど, シニトロフェノール感受性は高かつた. ペントバルビタール前処置は甲摘群にわいて, ジニトロフェノール感受性に変化を見なかつたが, チ口 キシン投与群において, 明らかな感受性の低下を見た。

\section{I . 緒 言}

甲状腺ホルモンは uncoupler 2.4. ジニトロフェノール（以下，DNP と略す）の酸素消費量に対する感 受性を増加させる ${ }^{1) \sim 5}$. また交感神経㵂断䠼 Dibenzyline $e^{6)}$ ，Guanethidine $e^{7)}$ 等は甲状腺ホルモンによる酸素消 費量の増加を押える，以上の報告は，甲状腺ホルモンの酸素消費量に対する作用におけるミトコンドリアと 交感神経系の関係を示唆する．また中枢麻醉薬のペントバルビタールにも交感神経遮断剤同様の効果が認め られた ${ }^{8)}$. そてで甲状腺ホルモンの DNP 感受性増加作用を確かめ, その作用機序を明らかにする目的で, 甲摘及びチロキシン投与ラットを用い，その酸素消費量に対するDNP 及びペントバルビタールとDNPの 効果を検討し，知見を得たので報告する.

\section{II. 実験材料及ひ方法}

実験動物は, 雄性 Wister 系アルビノラット, 体重 250〜300 g のものを用いた. 甲状腺摘出は, 体重が $100 \sim 130 \mathrm{~g}$ 前後の時に, 外科的に行ない, 摘出後 20 日以上経過したものを用いた. チロキシン投与群は Lチロキシンナトリゥムを $100 \mu \mathrm{g} / 100 \mathrm{~g}$ 体重を 5 回連日腹腔内注射したものを用いた. ペントバルビタールは $5 \mathrm{mg} / 100 \mathrm{~g}$ 体重を腹腔内注射を行なつた. DNP は水酸化ナトリウムにて中和し, $0.5 \sim 2.0 \mathrm{mg} / 100 \mathrm{~g}$ 体重 を腹腔内注射を行なつた。串験 2 にわいて，DNP はペントバルビタール投与 30 分後に投与した。酸素消費

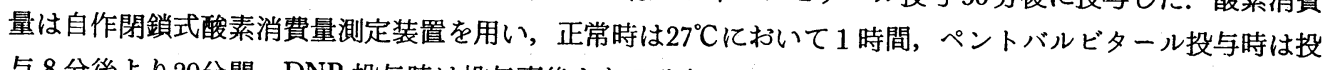
与 8 分後より 20 分間, DNP 投与時は投与直後より 5 分毎に 3 時間測定した.

\section{III. 実 験 結 果}

1. DNP の酸素消费量に対する効果 (Table 1, Fig. 1 (a) (b) (c))

DNP 投与による酸素消費量の增加を正常時の酸素消費量に対するパーセントで表わしたものを感受性と して表わした. DNP 投与量が $5 \mathrm{mg} / \mathrm{kg}$ の場合は DNP 感受性の最高值は甲状脉状態により差がなかつたが, 甲摘群では最高值を示した後, 急速な感受性の低下を見た。 DNP 投与量が $10 \mathrm{mg} / \mathrm{kg}$ の場合は甲状腺状態 が高いはど感受性は高く, 甲摘群とチロキシン投与群では有意な感受性の差を見た. DNP 投与量が $20 \mathrm{mg} /$ $\mathrm{kg}$ の場合はコントロール群と甲摘群にわいて有意な感受性の差を見たが，チロキシン投与群にわいては DNP 投与量が大量のため最大の感受性を示す以前に死亡した。 
2. ペンバルヒヒタールとDNP の酸素消費量に対する効果 (Fig. 2)

ヘントバルビタール投与による酸素消費量の低下は, チロキシン投与群で最も大きく, 甲摘群, コントロ 一ル群であるてとが確認された。DNP 投与量は甲状腺状態によりDNP 感受性は明らかな差のでるように 甲艦やよびコントロール群においては $20 \mathrm{mg} / \mathrm{kg}$ を用いたが，チロキシン投与群においてはその薬用量では 大昷受性を示す以前に死亡するため， $10 \mathrm{mg} / \mathrm{kg}$ を用いた。甲摘群ではペントバルビタールの前処置が DNP 感受性にほとんど効果がないのに比べ，チロキシン投与群では明らかな感受性の低下を見た。

Table 1. Oxygen consumption and DNP-induced calorigenesis in hypothyroid, normal and hyperthyroid rats

\begin{tabular}{c|l|l|l|c}
\hline $\begin{array}{c}\text { Dose } \\
\mathrm{mg} / \mathrm{kg}\end{array}$ & Thyroid State & $\mathrm{N}$ & $\begin{array}{l}\text { oxygen } \\
\text { consumption } \\
\left(1 / \mathrm{hr} / \mathrm{kg}^{3 / 4}\right)\end{array}$ & $\begin{array}{c}\text { DNP-induced } \\
\text { calorigenesis } \\
\%\end{array}$ \\
\hline \multirow{3}{*}{5} & Hypothyroid & 4 & $1.04 \pm 0.04$ & $22.0 \pm 6.8$ \\
& Normal & 4 & $1.39 \pm 0.09$ & $33.1 \pm 4.2$ \\
& Hyperthyroid & 4 & $1.67 \pm 0.08$ & $25.6 \pm 4.9$ \\
\hline \multirow{3}{*}{10} & Hypothyroid & 4 & $0.93 \pm 0.05$ & $27.6 \pm 5.9$ \\
& Normal & 4 & $1.34 \pm 0.04$ & $43.2 \pm 10.1$ \\
& Hyperthyroid & $4\left(1^{\mathrm{a}}\right)$ & $1.85 \pm 0.05$ & $64.3 \pm 11.2$ \\
\hline \multirow{3}{*}{20} & Hypothyroid & 4 & $1.02 \pm 0.06$ & $64.6 \pm 15.3$ \\
& Normal & $4\left(3^{\mathrm{b}}\right)$ & $1.49 \pm 0.12$ & $111.3 \pm 19.7$ \\
& Hyperthyroid & $4\left(4^{\mathrm{c}}\right)$ & $1.99 \pm 0.06$ & $71.2 \pm 10.3$ \\
\hline
\end{tabular}

Each group describes the averege value of four rats (Mean values \pm Standard error) a. Died with in $60 \mathrm{~min}$. b. Died with in $120 \mathrm{~min}$. c. Died with in $15 \mathrm{~min}$.

Fig. 1. Effects of DNP on oxygen consumption in hypothyroid, normal and hyperthyroid rats
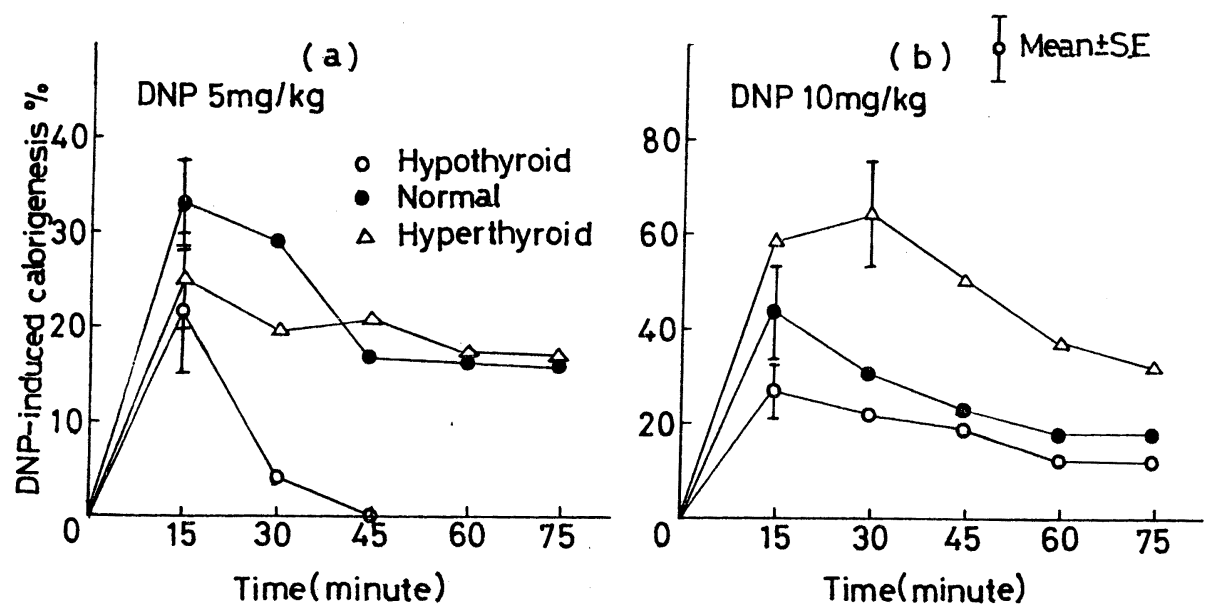


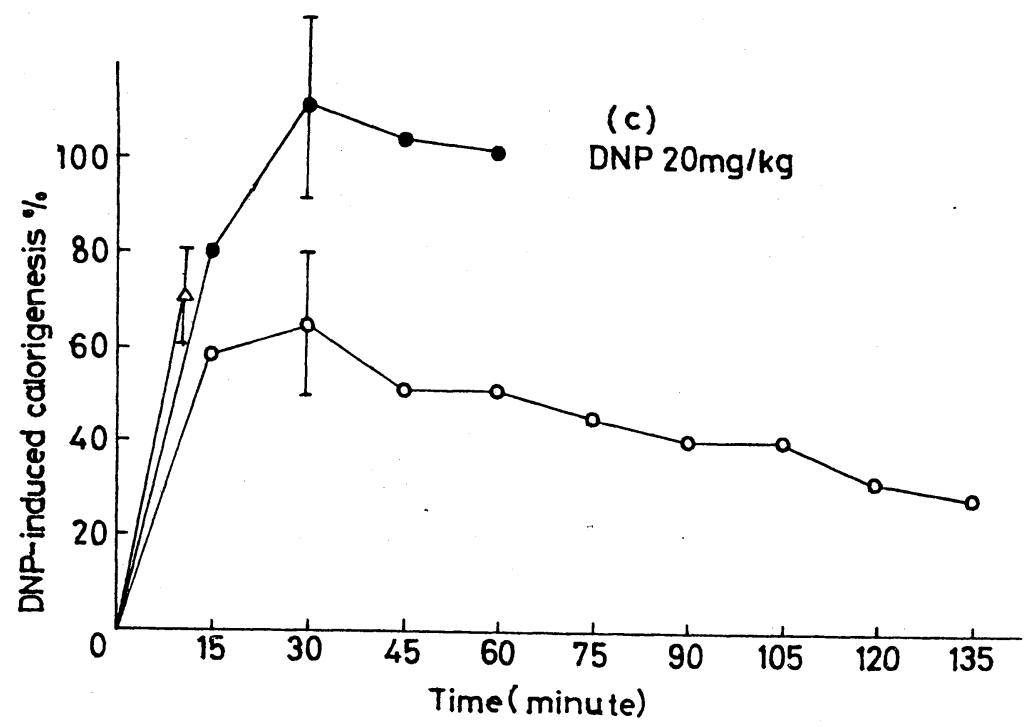

Fig. 2. Effects of pentobarbital and DNP on oxygen consumption in hypothyroid, normal and hyperthyroid rats

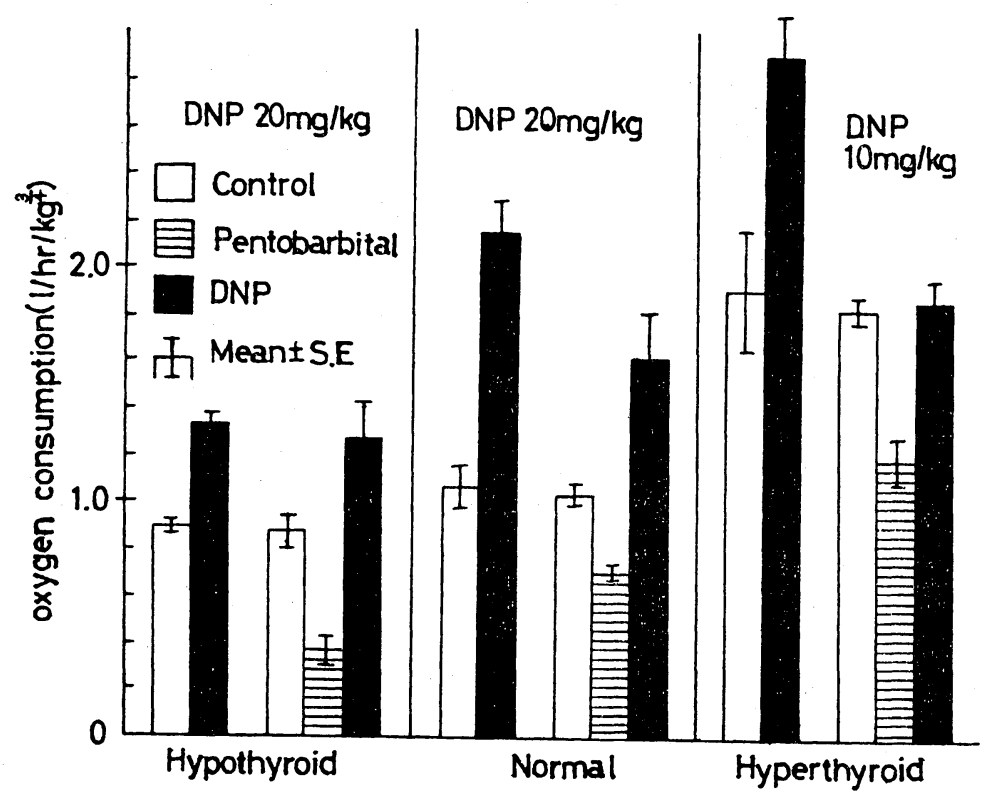

Each group describes the average values of four rats

$$
\text { IV. 考察 }
$$

甲状腺ホルモンによる DNP 感受性増加の作用機序について, Hoch") は甲状腺ホルモンの作用として, 蛋 白合成によるミトコンドリア電子伝達成分の増加だけを考えたのでは ${ }^{9) \sim 12)}$, DNP はすべてのミトコンドリ アに同様に作用するので, 呼吸調節を低下させ, 酸素消費量を増加させる割り合いに変化はないと述べてい 
ろ.さらに Hoch はチロキシンが血漿蛋白と結合し，free DNP を増加させる可能性 ${ }^{13114) ， チ ロ キ シ ン か ゙ ~}$ DNP の分野を抑制する可能性も否定し，甲状腺ホルモンはミトコンドリアに直接作用し，永久的な変化を るとし，DNP に対する感受性を高めるものと主張している ${ }^{15)}$. 肝ミトコンドリアは DNP 投与後数分で最

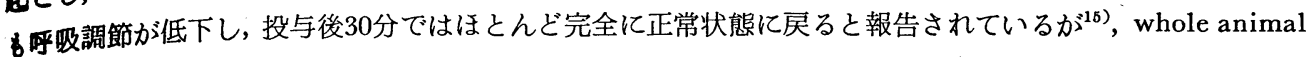
にわける酸素消費量の增加は DNP 投与後15３0分で最大となり，以後徐々に低下した．てれは DNP の作 用部位として，骨格筋の重要性を示唆する．DNP による酸素消費量の増加は甲摘群においても見られるて と，DNP 投与量が低い時は甲状腺状態により感受性の差が見られなかつたとと，DNP 投与量が高い時は甲 状脉状態により感受性の差が見られたととは，DNP の酸素消費量増加作用に甲状腺ホルモンが関与するも のと, 甲状腺ホルモンを必要としないものの二つの機序があるてとが推定される.ペントバルビタールは骨 格筋が重要と考元られる交感神経系を介した熱産生機構を遮断するが8)，甲状腺ホルモンによるDNP 感受 性增加をも押光た，以上のととから，甲状腺ホルモンが関与する熱産生機構は交感神経系により活性化され ろが,さらにその部位をDNP が活性化するものと考えられる.

本踰文要旨は, 第43回日本内分觉会総会に於て発表した。

文献

1) Hoch, F.L. : Physiol. Rev., $42: 605$, (1962). $\quad$ 2) Aiwall, N. : Skand. Arch. Physiol., Suppl.
$72: 1$, (1936).
3) Hoch, F.L. : Fed. Proc., $23: 433$, (1964).
4) Hoch, F.L. :

Endocrinology, $76: 335$, (1965).

5) Hoch, F.L. : Endocrinology, $77: 991$, (1965).

Ramey, E.R., Bernstein, H. \& Goldstein, M.S. : Fed. Proc., $14: 118$, (1955). 7) Gaffney, T.E.

\& Braunwald, E. : J. Clin. Invest., 40 : J. Clin. Invest., $40: 1040$, (1961). 8) 倉橋昌司：日内 分泌誌, $46: 796$ (1970). $\quad$ 9) Tata, J.R. : Nature, $197: 1167$, (1963). 10 ) Weiss, W.P., \& L. Sokoioff : Science, $140: 1324$, (1963). 11) Ernster, L., \& R. Luft : Advances Metabol. Dis., $1: 95$, (1964). $\quad$ 12) Tata, J.R., L. Ernster, O. Lindberg, E. Arrhenius, S. Pedersen, \& R. Hedman : Biochem. J., 86 : 408, (1963). 13) Osorio, C. : J. Physiol. 163 : 151, (1962). 14) Hershman, J.M. : Endocrinology, $72: 799$, (1963).

15) Hoch, F.L. : Arch. Biochem. Bio phys., $124: 248$, (1968). 